
\title{
$\begin{array}{ll}\text { Research Square } & \begin{array}{l}\text { Preprints are preliminary reports that have not undergone peer review. } \\ \text { They should not be considered conclusive, used to inform clinical practice, } \\ \text { or referenced by the media as validated information. }\end{array}\end{array}$ \\ Environmental Risk Assessment of Industrial by- product Gypsum Utilized in Filling Abandoned Mine
}

\section{XueHong Du}

China University of Mining and Technology

Xiangdong Li ( $\nabla$ 4549@cumt.edu.cn )

China University of Mining and Technology https://orcid.org/0000-0001-9546-9175

\section{Qiyan Feng}

China University of Mining and Technology

Lei Meng

China University of Mining and Technology

Yue Sun

China University of Mining and Technology

\section{Research}

Keywords: Industrial solid waste gypsum, Coal mine back-filling, Leaching of metal elements, Patterns of migration

Posted Date: June 11th, 2021

DOl: https://doi.org/10.21203/rs.3.rs-605222/v1

License: (c) (i) This work is licensed under a Creative Commons Attribution 4.0 International License.

Read Full License 


\title{
Environmental risk assessment of Industrial by-product gypsum utilized in filling abandoned mine
}

\author{
XueHong Du ${ }^{1}$, Xiangdong $\mathrm{Li}^{1}$, Qiyan Feng ${ }^{1}$, Lei Meng ${ }^{2,3}$, Yue Sun ${ }^{4}$
}

\begin{abstract}
${ }^{1}$ School of Environment Science and Spatial Informatics, China University of Mining and Technology, Xuzhou 221116, China
${ }^{2}$ The National \& Local Joint Engineering Laboratory of Internet Application Technology on Mine, China University of Mining \& Technology, 221008, Xuzhou, Jiangsu Province, China.
\end{abstract}

${ }^{3}$ IoT Perception Mine Research Center, China University of Mining \& Technology, 221008, Xuzhou, Jiangsu Province, China. 4Jiangsu Vocational Institute of Architectural Technology, No.26 xueyuan Road, Xuzhou 221433, China

Corresponding author:

Xiangdong Li, School of Environment Science and Spatial Informatics, China University of Mining and Technology, Xuzhou 221116, China

Email: xdli123@126.com

Tel: +8613813460754

\begin{abstract}
This paper conducts sequential batch extraction experiments on phosphorus gypsum, titanium gypsum and desulfurized gypsum to explore their leaching characteristics and evaluate the hazards of the three types of gypsum. In addition, COMSOL Multiphysics is used to numerically solve the filling models of the three gypsum materials and the patterns of migration of metal elements in gypsum are observed. The result show that the leaching concentration of metal elements of the three gypsums is much lower than the leaching toxicity identification standard, so none of the three have the characteristics of leaching toxicity, and they are not classified as hazardous solid wastes; phosphorus gypsum and FGD gypsum are easier to release metal elements under low $\mathrm{pH}$ conditions, while the release of metal elements in titanium gypsum is not obvious under acidic conditions; the simulation results show that the diffusion concentration of metal elements increases with the passage of time, and its migration ability decreases with the increase of depth. The three gypsums can be considered as filling material for abandoned mines. During the filling process, the diffusion rate, diffusion distance and final concentration of metallic elements in gypsum are all affected by the initial concentration.
\end{abstract}

Keywords Industrial solid waste gypsum; Coal mine back-filling; Leaching of metal elements; Patterns of migration

\section{Introduction}

Circular economy has become an important way for global green development and resource protection. Green and low-carbon circular development is the basic policy to solve China's resource, environmental and ecological problems. The amount of industrial by-product gypsum produced in China is huge and which contains some toxic substances, improper disposal will cause long-term environmental pollution. The literature (Yang 2018) indicated that acid or non-acid precipitation will leach out the acidic substances from the gypsum during the stacking, and the leaching solution is strongly acidic which will pose a serious threat to environment (Tayibi et al. 2009; Chindaprasirt et al. 2011). Ning (Ning et al. 2018) found that the water-leaching concentration of $\mathrm{Zn}, \mathrm{Pb}$ and $\mathrm{As}$ in soil near the phosphorus gypsum storage site decreased with the increase of soil depth. Wei (Wei et al. 2015) studied the leaching characteristics and environmental effects of titanium gypsum, and found that titanium gypsum had higher metal releasing ability during solid-liquid leaching, and the high salinity condition was more 
conducive to release metal elements. Thus the sea water and salinization areas should be avoided during the storage and treatment of titanium gypsum. Flue gas desulfurization gypsum (FGDG) is a by-product of wet flue gas desulfurization (FGD) process. Hao (Hao et al. 2017) adopted the selective sequential extraction method to analyze the chemical speciation of harmful trace elements (HTEs) in FGD gypsum which collected from 12 power plants in Shanxi Province, result indicated that the order of average concentration of heavy metals was $\mathrm{Zn}>\mathrm{Cr}>\mathrm{Mn}>\mathrm{Ni}>\mathrm{Pb}>\mathrm{Cd}$, and the order of heavy metals migration is $\mathrm{Cd}>\mathrm{Mn}>\mathrm{Ni}>\mathrm{Pb}>\mathrm{Zn}>\mathrm{Cr}$. The leaching characteristics of mercury in FGD gypsum samples of 70 power plants by Hao (Hao et al. 2016) in an elaborate study using toxicity characteristic leaching procedure and synthetic precipitate leaching, which showed that mercury in FGD gypsum mainly existed in strong complex phase and had low migration ability. Sun (Sun et al. 2006) simulated acid rain condition to study the leachability of mercury in FGD gypsum. Release of mercury ions was found to be increased with decrease of $\mathrm{pH}$ value.

Gypsum is a cost-effective material with a potential of use in filling abandoned mines. If it is reasonably and comprehensively utilized, not only can the secondary environmental pollution problem be effectively controlled, but also the primary mineral resources can be largely replaced to achieve source reduction, harm reduction and resources, which is of great significance for improving the quality and efficiency of the circular economy. Zhang (Zhang et al. 2017) used phosphorus gypsum as filling aggregate, the mechanical properties of the fill body could meet the needs of underground mining for the strength of the filling. Li (Li et al. 2020) made use of different by-product gypsum such as FGD gypsum and phosphorus gypsum as material for the cemented filler, and studied the compressive strength and expansion rate of fillers. However, they found that there was no obvious effect on the compressive strength and expansion rate of different by-product gypsum and it is feasible to prepare full-solid cemented filler with by-product gypsum.

The application of industrial by-product gypsum in mine filling will reduce the cost and increase the environmental benefits, which will be bound to become the development direction of filling materials in the future. However, the gypsum component contains harmful trace metal elements (HTEs), and natural precipitation, groundwater as well as acid mine drainage (AMD) contact with gypsum during filling process will cause the release of trace elements and cause inevitable damage to the environment, such as Fig.1 (Song et al. 2017; Bai et al. 2013). Therefore, this work studied the leaching characteristics of metal elements in phosphorus gypsum, titanium gypsum and FGD gypsum, and evaluated the hazards of gypsum as a filling material.

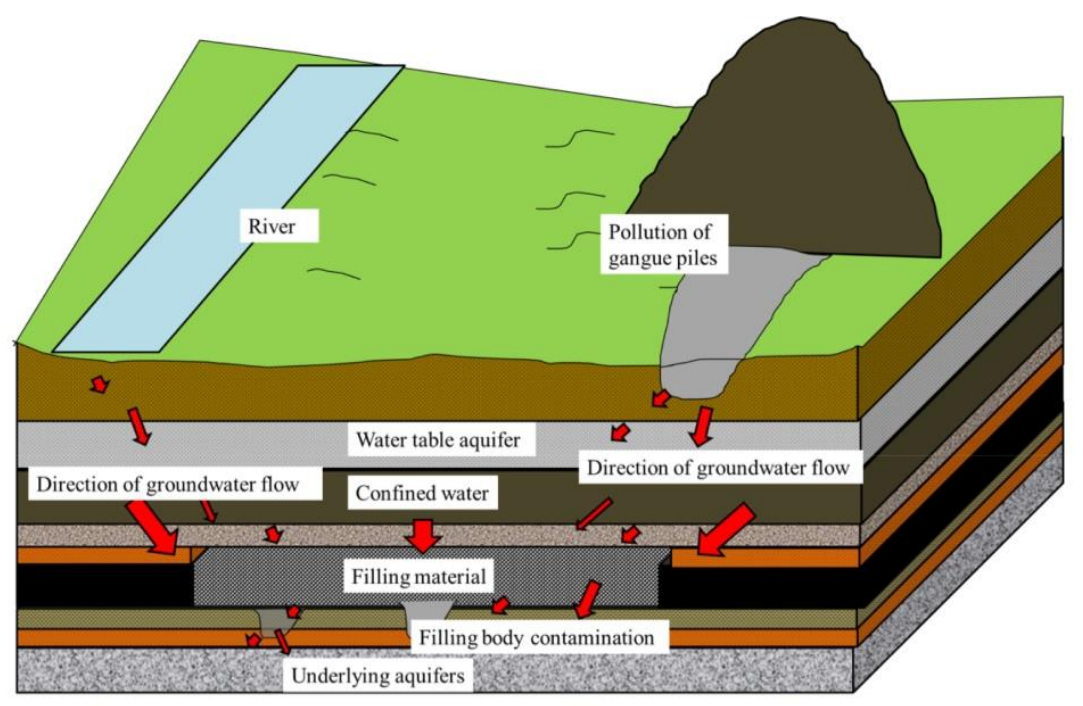

Fig.1 Potential effects of coal gangue in goaf on groundwater environmrnt 


\section{Methods}

\section{Gypsum samples}

Phosphorus gypsum, titanium gypsum and FGD gypsum used in the experiment were collected from a phosphate fertilizer plant, titanium powder plant and thermal power plant respectively. All samples should be placed in an oven at $328 \mathrm{~K}$ to dry for $19 \mathrm{~h}$ before the experiment for later use.

\section{Sequential batch extraction leaching}

Sequential batch extraction process is performed by replacing fresh leaching medium regularly in the process of leaching experiment to simulate the leaching condition where the disposed of gypsum will experience repetitive percolation of rain water and/or AMD solution of low $\mathrm{pH}$ and the leachate will coexit with gypsum for a considerable period of time. The repetitive extractions give us an idea about the highest concentrations of each constituent that is likely to leach out in a natural environment (Dutta et al. 2009).

In a typical run $40 \mathrm{~g}$ of each of three gypsum samples was extracted with $200 \mathrm{ml}$ dilute $\mathrm{H} 2 \mathrm{SO} 4 \mathrm{pH}=1.8$ and 3.1) respectively for a week. Separate gypsum from extracting medium, then fresh dilute sulfuric acid was added and continued for another week. The same procedure was repeated in four cycles. Each cycle of the leachate was collected, $\mathrm{pH}$ of the leachate was noted and trace elements in leachate were analyzed. A series of experiments were done by the above procedure with $\mathrm{NaOH}$ solutions $(\mathrm{pH}=10.4$ and 11.7).

The concentrations of elements (expect As, $\mathrm{Hg}$ ) in the leachate were determined by inductively coupled plasma emission spectrometry (ICP). The concentration of As and Hg in the leachate were estimated by using atomic fluorescence analysis (AFS).

\section{Numerical simulation of heavy metal element migration}

Taking the working face of a mining area as the research background, the length of the working face is $120 \mathrm{~m}$ and nearly horizontal, the filling area and the floor rock constitute a system of upper and lower media. Floor rock is limestone with a thickness of $20 \mathrm{~m}$, and the thickness of filling body is $5 \mathrm{~m}$. The model is divided by free triangle mesh and the mesh of filling area is added to ensure the reliability of results. The whole mesh consists of 2525 domain units and 265 side units. In order to better observe the migration of metal elements in filling process, an observation point was set at the middle line of working face and the center of the bottom of filling area, with the coordinate $(60,-5)$. Specific boundary labels of the model and the specific location of the observation point are shown in Fig.2.

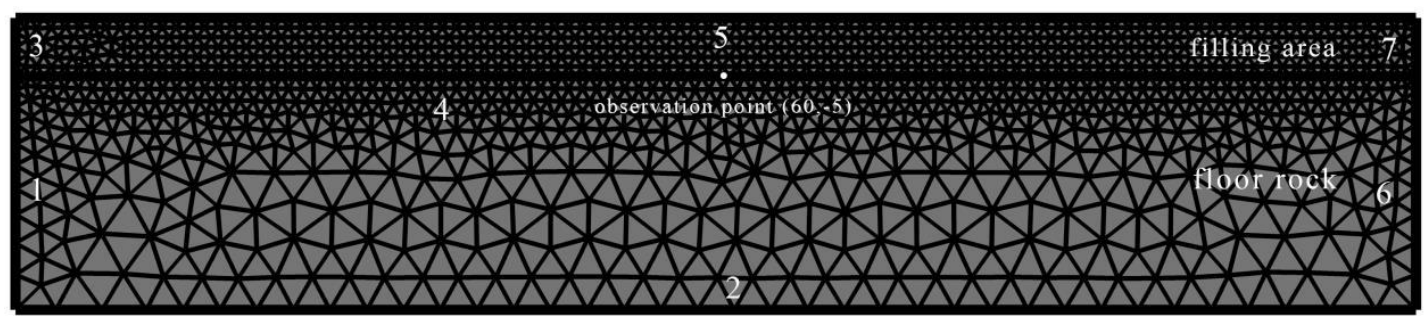

Fig.2 Filling mine numerical subdivision model

The Subsurface Flow Module in the COMSOL Multiphysics software has the most commonly used basic differential equations and boundary conditions in the calculation of seepage flow. The Darcy equation model is a general seepage equation based on Darcy's law and the continuity equation of water flow. The expression is:

$\frac{\partial}{\partial \mathrm{t}}(\rho \varepsilon)+\nabla \cdot \rho\left[-\frac{\mathrm{k}}{\mu}(\nabla \mathrm{p}+\rho \mathrm{g} \cdot \nabla \mathrm{D})\right]=\mathrm{Q}_{\mathrm{m}}$ 
Where $\varepsilon$ is porosity; $\rho$ is fluid density $\left(\mathrm{kg} \cdot \mathrm{m}^{-3}\right)$; $\mathrm{k}$ is permeability; $\mu$ is fluid viscosity (Pa.s); $\mathrm{p}$ is pressure $(\mathrm{Pa})$; $\mathrm{D}$ is the direction that represents vertical elevation $(\mathrm{m}) ; \mathrm{Q}_{\mathrm{m}}$ is the source item.

In addition, the equation used to describe fluid flow in saturated unsaturated porous media in this software is Richards equation:

$\rho\left(\frac{C_{w}}{\rho g}+S_{C} S\right) \frac{\partial p}{\partial t}+\nabla \cdot \rho\left[-\frac{K_{s}}{\mu} K_{r}(\nabla p+\rho g \cdot \nabla D)\right]=Q_{m}$

Where $C_{w}$ is water capacity, $S_{c}$ is effective saturation (dimensionless), $S_{c}=\left(\theta_{s}-\theta_{r}\right) /(1 m \cdot \rho g)$, where $\theta_{s}$ and $\theta_{r}$ denote the volume fraction of fluid at saturation and after drainage, respectively; $S$ is a storage coefficient $\left(\mathrm{m}^{-1}\right), K_{S}$ is saturated Permeability, $K_{r}$ is relative permeability.

Assuming that the fluid does seepage motion only under the action of gravity, it conforms to Darcy's law of motion:

$\mathrm{u}=-\frac{\mathrm{K}}{\mu} \nabla \mathrm{p}$

Where $\mathrm{u}$ is the fluid seepage velocity vector $\left(\mathrm{m} \cdot \mathrm{s}^{-1}\right)$.

In the process of pollutant migration, both molecular diffusion and mechanical dispersion follow Fick's first law, and these two effects occur at the same time and because dispersion and diffusion are difficult to distinguish, the two are generally referred to as the hydrodynamic dispersion coefficient:

$\frac{\partial}{\partial x}\left(D_{h} \frac{\partial C}{\partial x}\right)-\frac{\partial}{\partial x}(u C)=\frac{\partial C}{\partial t}$

Where $D_{h}$ is the hydrodynamic dispersion coefficient.

\section{Initial value and boundary conditions}

Assuming that the goaf is full of water, the gravitational potential energy of the mine water produces a pressure head on the floor, combined with the experimental results of the metal elements release law in gypsum, take $\mathrm{Zn}$ as an example for numerical simulation. The initial value of the inflow concentration is the final leaching concentration of $\mathrm{Zn}$ when deionization is used as the leaching medium. The boundary conditions and governing equations are shown in Table 1.

Table 1 Setting of boundary conditions

\begin{tabular}{llcl}
\hline Component & Boundary conditions & equation & $\begin{array}{l}\text { boundary } \\
\text { labels }\end{array}$ \\
\hline $\begin{array}{lll}\text { Richards' } \\
\text { Equation(dl) }\end{array}$ & Pressure head & $H_{p}=\frac{p}{\rho g}$ & $3,4,7$ \\
& No flow & $-\mathrm{n} \cdot \rho \mathrm{u}=0$ & $1,2,6$ \\
$\begin{array}{l}\text { Transport of Dilutrd } \\
\text { Species in Porous } \\
\text { Media (tds) }\end{array}$ & No flux & $-\mathrm{n} \cdot J_{j}=0$ & $1,3,6,7$ \\
& Outflow & $c_{j}=c_{0, j}$ & 5 \\
\hline
\end{tabular}

Table 2 Values of parameters in the model

\begin{tabular}{lll}
\hline Variable Units & Description & Value \\
\hline
\end{tabular}




\begin{tabular}{llll}
\hline Ks & $\mathrm{m} \cdot \mathrm{d}^{-1}$ & Saturated hydraulic conductivity & $2.94 \mathrm{E}-4$ \\
$\theta_{\mathrm{s}}$ & & Porosity/void fraction & 0.25 \\
$\theta_{\mathrm{r}}$ & & Residual saturation & 0.01 \\
$\rho$ & $\mathrm{kg} \cdot \mathrm{m}^{-3}$ & fluid density & $1 \mathrm{E}+3$ \\
$\mathrm{Dm}$ & $\mathrm{m}^{2} \cdot \mathrm{d}^{-1}$ & Coefficient of molecular diffusion & $1 \mathrm{E}-9$ \\
$\mathrm{H}_{\mathrm{p}}$ & $\mathrm{m}$ & pressure head & 5 \\
$\mu$ & $\mathrm{Pa} \cdot \mathrm{s}$ & fluid viscosity & $0.89 \mathrm{E}-3$ \\
\hline
\end{tabular}

\section{Result}

\section{Sequential batch extraction}

\section{Changes of $\mathrm{pH}$ of the leachate}

The time evolution of the $\mathrm{pH}$ of the leachates for different leaching media (dilute $\mathrm{H}_{2} \mathrm{SO}_{4} \mathrm{pH}-1.8$ and 3.1; deionized water; dilute $\mathrm{NaOH}$ pH-10.3 and 11.7) at a solid-liquid ratio of 1:5 is shown in Fig.3. Leaching was done in 4 cycles spanning a seven-day period.

Most of the leachate of phosphorus gypsum is strong acidity, probably because deionized water or acidic leaching medium can effectively leach out residual acidic substances in phosphorus gypsum. As the $\mathrm{pH}$ of the leaching medium increases, the $\mathrm{pH}$ of the leachates change correspondingly, especially under neutral and alkaline conditions, the $\mathrm{pH}$ of the leachates gradually approaches the neutral during the continuous leaching process. However, the $\mathrm{pH}$ change of leachate which leached under low $\mathrm{pH}$ condition is not obvious and always shows strong acidity, indicating that the $\mathrm{pH}$ of leachate under strong acidic condition is not affected by time (Fig.3a). However, the pH changes of FGD and titanium gypsum leachates showed obvious effect over time. Under the condition of initial $\mathrm{pH}$ of 11.7, the $\mathrm{pH}$ value of the leachate of FGD gypsum increased significantly, but under $\mathrm{pH}$ of $1.8,3.1$ and 10.3, there was no significant increase in the $\mathrm{pH}$ of the extract and finally appeared neutral and weakly alkaline (Fig.3b). The $\mathrm{pH}$ of the leachate obtained from titanium gypsum in acidic or alkaline leaching medium with the time is similar to that of the deionized water leachate. In the first period, leachates under all conditions showed weak acidity, and continued leaching until the $\mathrm{pH}$ increased in the second period, showed weak alkalinity. After that, the $\mathrm{pH}$ gradually decreased as the extraction time extended and appeared to neutral.
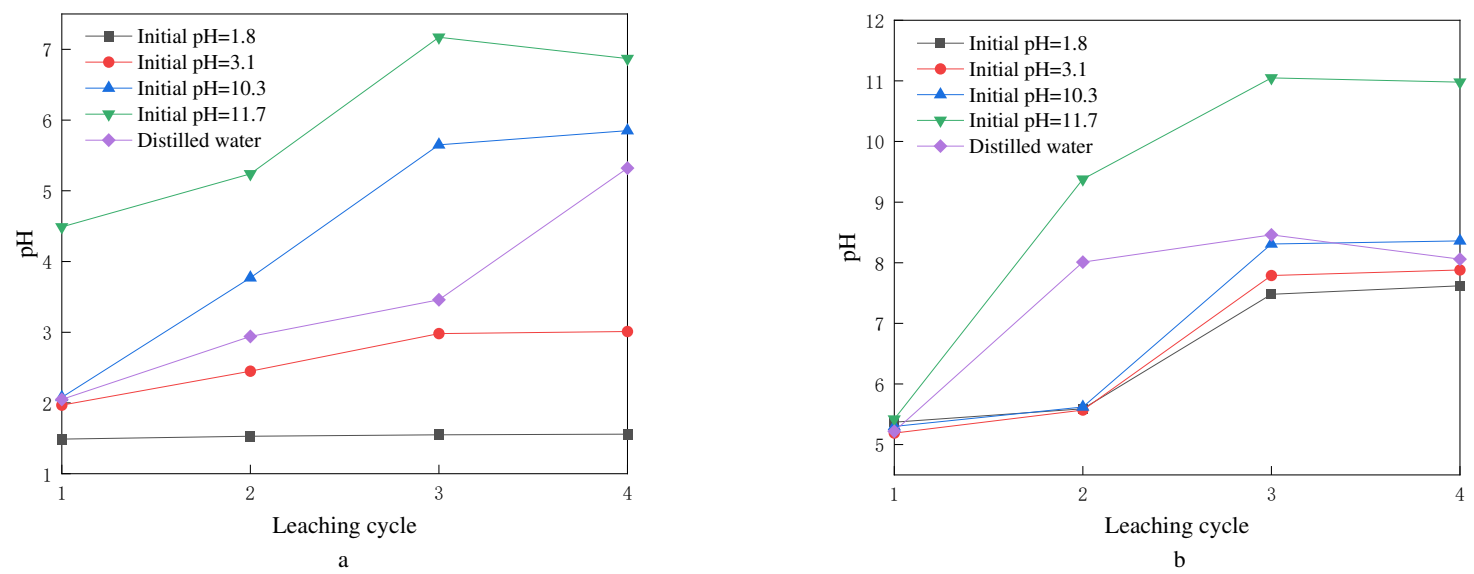


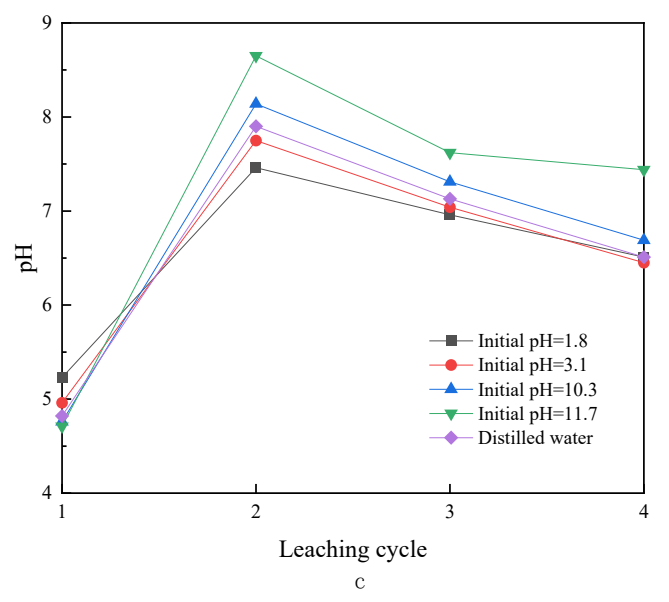

Fig.3 Change rule of pH of leachates (a: phosphorus gypsum; b:FGD gypsum c:titanium gypsum)

\section{Leaching of metal elements}

As shown in Fig.4 a and d, the leaching characteristics of $\mathrm{Zn}$ and $\mathrm{Mn}$ in phosphorus gypsum are relatively similar. The leaching concentration of metal elements decrease with the increase of pH (expect for deionized water). At $\mathrm{pH}=11.7$, the released metal elements concentration is the smallest, this shows that the alkaline condition is not conducive to the leaching of metal elements in phosphorus gypsum, which may be caused by the formation of phosphate precipitation of metal elements under alkaline conditions. During the release process of $\mathrm{Mn}$, the element concentration released in the leaching medium with the initial $\mathrm{pH}$ of 1.8 is the largest, followed by deionized water and both of them is very similar. And during the release process of $\mathrm{Zn}$ element, only in the first cycle, the concentration under the condition of $\mathrm{pH}=1.8$ is the largest, from the second cycle to the fourth cycle, the concentration released when deionized water is the leaching medium is the largest. In addition, the concentration of leached metal elements gradually decreased under all conditions and the concentration is close to 0 in the fourth period. This indicates that when phosphorus gypsum is exposed to acidic solvents (such as acid rain or acidic mine water) or nonacid precipitation will promote the release of metal elements in phosphorus gypsum, and the concentration of metal elements released is gradually reduced during repeated contact.

The concentration of $\mathrm{Zn}$ released by titanium gypsum in alkaline conditions is greater than that in acidic conditions and the leachate is in weakly alkaline state from the second cycle (Fig.4 b). Because titanium gypsum has a buffering effect on acid (Wei et al. 2015), although the acidic leaching medium can consume the alkalinity of titanium gypsum itself, the $\mathrm{pH}$ decreases slowly, making the release of metal elements in low pH conditions less obvious. Fig.4 e shows the change rule of Mn element leaching concentration in titanium gypsum. It can be seen that, except for the leaching medium with an initial $\mathrm{pH}$ of 1.8, the leaching concentration of $\mathrm{Mn}$ under other conditions is quite low and even below the detection limit. This may be because the $\mathrm{pH}$ of the leachate in the first cycle is weakly acidic, indicating that the acidic condition has a certain effect on the release of metal elements in titanium gypsum, and then with the increase of $\mathrm{pH}$ the concentration of $\mathrm{Mn}$ is significantly reduced. When extracting $\mathrm{Mn}$ elements from gypsum by a leaching medium of $\mathrm{pH}=11.7$, only very small amounts of Mn were released in the first cycle, and the rest were below the detection limit. This may be because $\mathrm{Mn}$ is in a weakly alkaline condition, the form of oxyhydroxide or hydroxide precipitates or adsorbed in the solid phase, resulting in extremely small amounts in the leachate even lower than the detection limit.

It can be seen from Fig. $4 \mathrm{c}$ and $\mathrm{f}$ that the metal elements in FGD gypsum are more easily released in the low $\mathrm{pH}$ leaching medium. The leaching concentration changes of $\mathrm{Zn}$ and $\mathrm{Mn}$ are similar, both are liable to be leached under acidic conditions and the concentration under each condition gradually decreases and becomes stable with the extension of time. The release concentration of $\mathrm{Zn}$ and $\mathrm{Mn}$ is the largest in the 
leaching medium with $\mathrm{pH}=1.8$, because the FGD gypsum has more impurities and its structure is relatively loose. Under acidic conditions, higher concentrations of $\mathrm{H}^{+}$will destroy the structure of FGD gypsum, so that the metal elements are replaced by $\mathrm{H}^{+}$from the gypsum particles and dissolved into the water phase. Under alkaline conditions, the leaching amount of Mn in FGD gypsum is extremely weak, and even during the entire leaching process at $\mathrm{pH} 11.7$, the concentration of $\mathrm{Mn}$ is lower than the detection limit, which may be due to the presence of $\mathrm{Mn}$ in the form of precipitation under strong alkaline conditions. However, the $\mathrm{Zn}$ is still released under strong alkaline conditions, probably because $\mathrm{Zn}$ is combined with hydroxyl groups to form soluble substances, which will be leached in strong alkaline leaching medium.
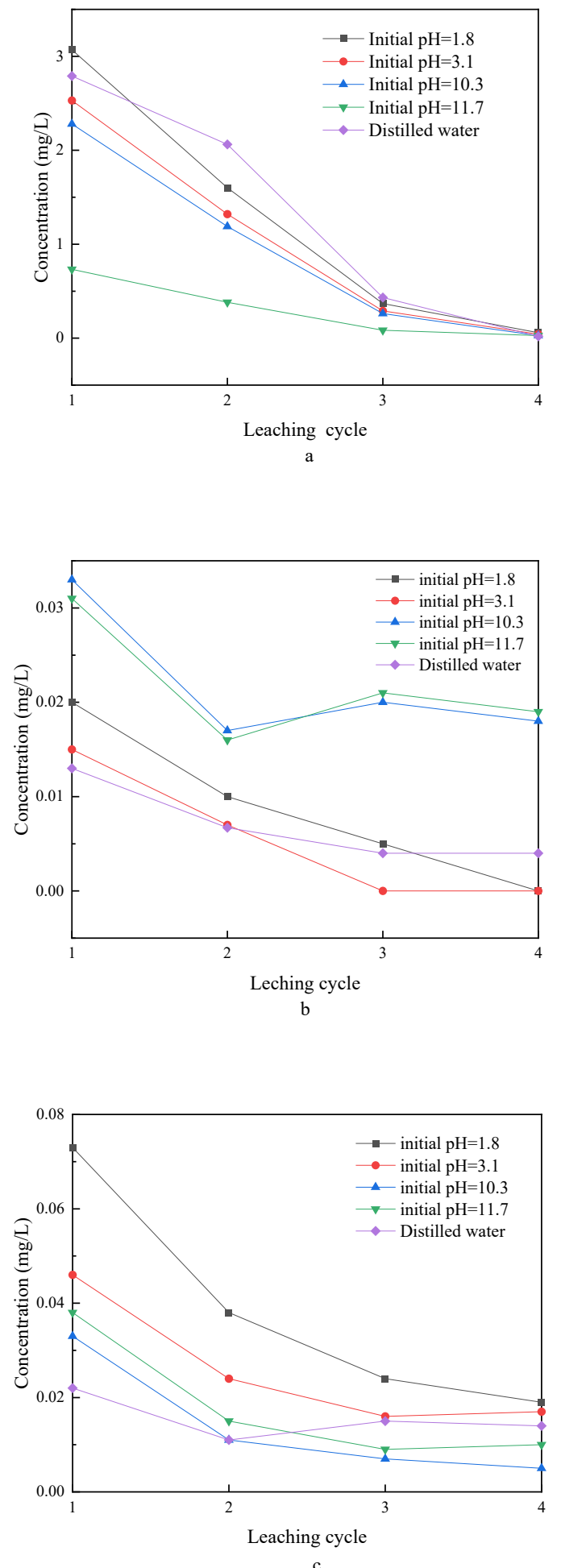

c
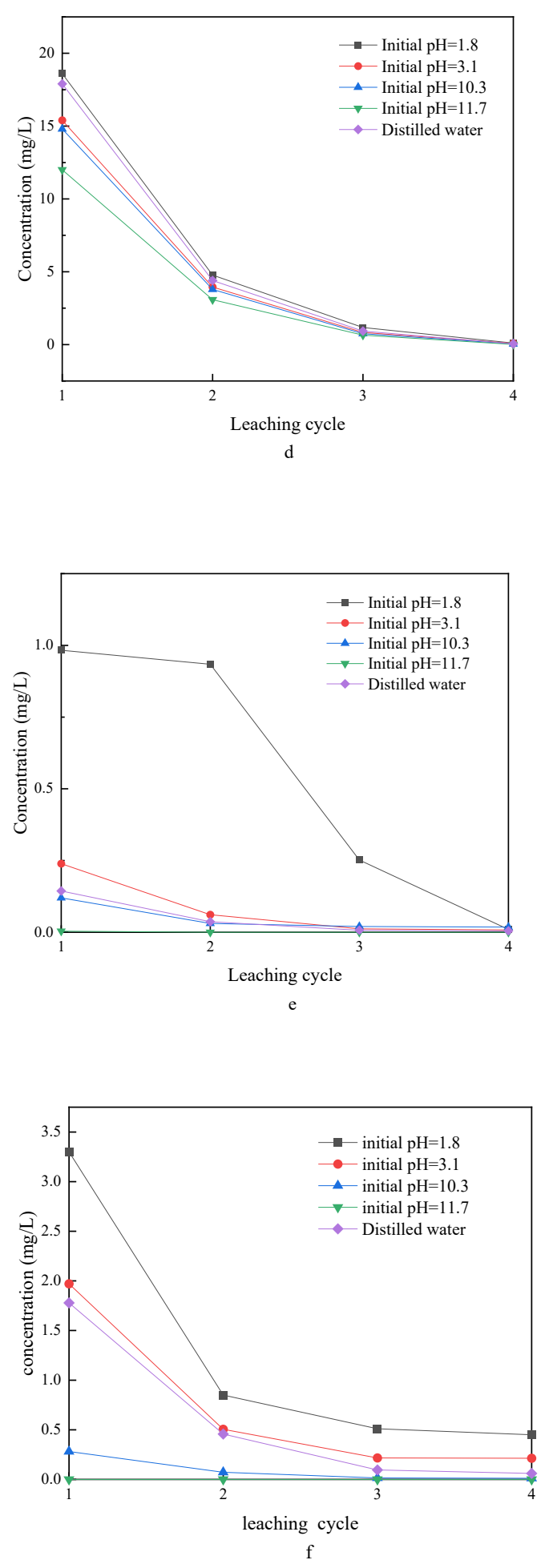
Fig.4 Leaching concentration of Zn in phosphorus gypsum(a), titanium gypsum(b) and FGD gypsum(c); leaching concentration of $\mathrm{Mn}$ in phosphorus gypsum(d), titanium gypsum(e) and FGD gypsum(f)

According to the above-mentioned release law of $\mathrm{Mn}$ and $\mathrm{Zn}$, it is found that the leaching concentration of metal elements in the first cycle is the largest. Therefore, the following is to compare the leaching concentration of metal elements in the first period with the Identification standards for hazardous wastes-identification for extraction toxicity to judge the hazard of three types of gypsum. As shown in Table 2-4, the concentrations of metal elements leached from three gypsum samples are far below the leaching toxicity identification limit, indicating that phosphorus gypsum, titanium gypsum and FGD gypsum have no leaching toxicity characteristics and are not classified as hazardous solid waste.

Table 2 Concentration of metallic elements in phosphorus gypsum leach solution

\begin{tabular}{|c|c|c|c|c|c|c|}
\hline \multirow{2}{*}{ HTEs } & \multicolumn{5}{|c|}{ Phosphorus gypsum $\left(\mathrm{mg} \cdot \mathrm{L}^{-1}\right)$} & \multirow{2}{*}{$\begin{array}{l}\text { Limits } \\
\left(\mathrm{mg} \cdot \mathrm{L}^{-1}\right) \\
(\mathrm{GB} \quad 5085.3- \\
2007)\end{array}$} \\
\hline & Deionized water & $\mathrm{pH}=1.8$ & $\mathrm{pH}=3.1$ & $\mathrm{pH}=10.3$ & $\mathrm{pH}=11.7$ & \\
\hline As & 0.378 & 0.399 & 0.36 & 0.354 & 0.347 & 5 \\
\hline $\mathrm{Hg}$ & 0.0117 & 0.00547 & 0.0101 & 0.00956 & 0.00365 & 0.1 \\
\hline $\mathrm{Cd}$ & 0.074 & 0.082 & 0.067 & 0.06 & 0.035 & 1 \\
\hline $\mathrm{Cr}$ & 0.16 & 0.25 & 0.15 & 0.11 & ND & 15 \\
\hline $\mathrm{Pb}$ & 0.31 & 0.36 & 0.26 & 0.21 & ND & 5 \\
\hline $\mathrm{Zn}$ & 2.79 & 3.07 & 2.53 & 2.28 & 0.733 & 100 \\
\hline $\mathrm{Mn}$ & 17.9 & 18.6 & 15.4 & 14.8 & 12 & NG \\
\hline
\end{tabular}

Note: “ND" represents "not detected"; "NG" represents "not given"

Table 3 Concentration of metallic elements in titanium gypsum leach solution

\begin{tabular}{lllllll}
\hline & \multicolumn{2}{l}{ Titanium gypsum $\left(\mathrm{mg} \cdot \mathrm{L}^{-1}\right)$} & & & & $\begin{array}{l}\text { Limits } \\
\left(\mathrm{mg} \cdot \mathrm{L}^{-1}\right)\end{array}$ \\
\cline { 2 - 7 } HTEs & Deionized water & $\mathrm{pH}=1.8$ & $\mathrm{pH}=3.1$ & $\mathrm{pH}=10.3$ & $\mathrm{pH}=11.7$ & $\begin{array}{l}\text { (GB 5085.3- } \\
2007)\end{array}$ \\
\hline $\mathrm{As}$ & 0.0014 & 0.0007 & 0.001 & 0.0016 & 0.0129 & 5 \\
$\mathrm{Hg}$ & 0.00004 & $\mathrm{ND}$ & $\mathrm{ND}$ & $\mathrm{ND}$ & $\mathrm{ND}$ & 0.1 \\
$\mathrm{Cd}$ & $\mathrm{ND}$ & 0.008 & 0.005 & $\mathrm{ND}$ & $\mathrm{ND}$ & 1 \\
$\mathrm{Cr}$ & $\mathrm{ND}$ & 0.05 & 0.03 & $\mathrm{ND}$ & $\mathrm{ND}$ & 15 \\
$\mathrm{~Pb}$ & $\mathrm{ND}$ & $\mathrm{ND}$ & $\mathrm{ND}$ & $\mathrm{ND}$ & $\mathrm{ND}$ & 5 \\
$\mathrm{Zn}$ & 0.013 & 0.02 & 0.015 & 0.033 & 0.031 & 100 \\
$\mathrm{Mn}$ & 0.144 & 0.983 & 0.239 & 0.12 & 0.004 & $\mathrm{NG}$ \\
\hline
\end{tabular}

Note: "ND" represents "not detected"; "NG" represents "not given"

Table 4 Concentration of metallic elements in FGD gypsum leach solution 


\begin{tabular}{lllllll}
\hline & \multicolumn{2}{l}{ FGD gypsum(mg. ${ }^{-1}$ ) } & & & & $\begin{array}{l}\text { Limits } \\
\left(\mathrm{mg} \cdot \mathrm{L}^{-1}\right)\end{array}$ \\
\cline { 2 - 7 } & Deionized water & $\mathrm{pH}=1.8$ & $\mathrm{pH}=3.1$ & $\mathrm{pH}=10.3$ & $\mathrm{pH}=11.7$ & $\begin{array}{l}\text { (GB 5085.3- } \\
2007)\end{array}$ \\
\hline $\mathrm{As}$ & $\mathrm{ND}$ & 0.0005 & 0.0003 & $\mathrm{ND}$ & $\mathrm{ND}$ & 5 \\
$\mathrm{Hg}$ & $\mathrm{ND}$ & $\mathrm{ND}$ & $\mathrm{ND}$ & $\mathrm{ND}$ & $\mathrm{ND}$ & 0.1 \\
$\mathrm{Cd}$ & $\mathrm{ND}$ & 0.006 & $\mathrm{ND}$ & $\mathrm{ND}$ & $\mathrm{ND}$ & 1 \\
$\mathrm{Cr}$ & 0.03 & 0.08 & 0.05 & $\mathrm{ND}$ & $\mathrm{ND}$ & 15 \\
$\mathrm{~Pb}$ & $\mathrm{ND}$ & 0.07 & $\mathrm{ND}$ & $\mathrm{ND}$ & $\mathrm{ND}$ & 5 \\
$\mathrm{Zn}$ & 0.022 & 0.073 & 0.046 & 0.033 & 0.038 & 100 \\
$\mathrm{Mn}$ & 1.78 & 3.3 & 1.97 & 0.281 & $\mathrm{ND}$ & $\mathrm{NG}$ \\
\hline $\mathrm{Note}$ & & & & & & \\
\hline
\end{tabular}

Note: "ND" represents "not detected"; "NG" represents "not given"

\section{Numerical simulation result analysis}

COMSOL Multiphysics was adopted to numerically solve the models of phosphorus gypsum, FGD gypsum and titanium gypsum respectively, and the concentration distribution of $\mathrm{Zn}$ ions in different filling materials with a time of 200a was obtained, as shown in Fig.5. It can be seen from the figure that when the time is 200a, the highest heavy metal concentration distribution from different gypsum is in the filling body, and gradually weakens along the direction of the bottom plate. Moreover, the diffusion distance of Zn element in phosphorus gypsum, FGD gypsum, and titanium gypsum is significantly different. Since the permeability parameters of the three gypsums are similar, the diffusion distance of metal elements is affected by the initial concentration.
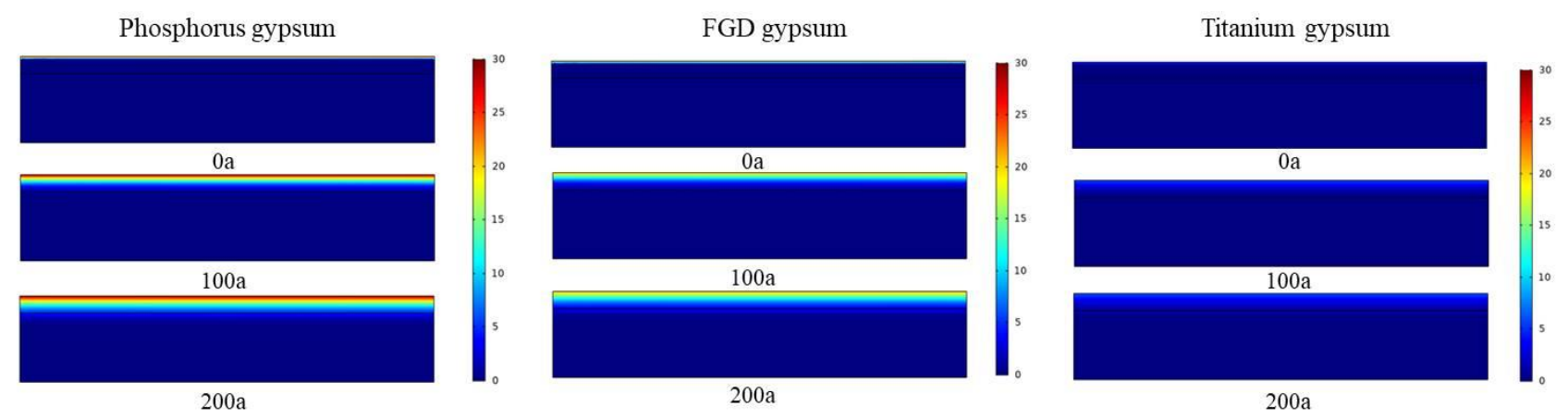

Fig.5 Cloud map of Zn concentration distribution at $0 \mathrm{a}, 100 \mathrm{a}$ and $200 \mathrm{a} .\left(10^{-5} \mathrm{~mol} \cdot \mathrm{m}^{-3}\right)$ 


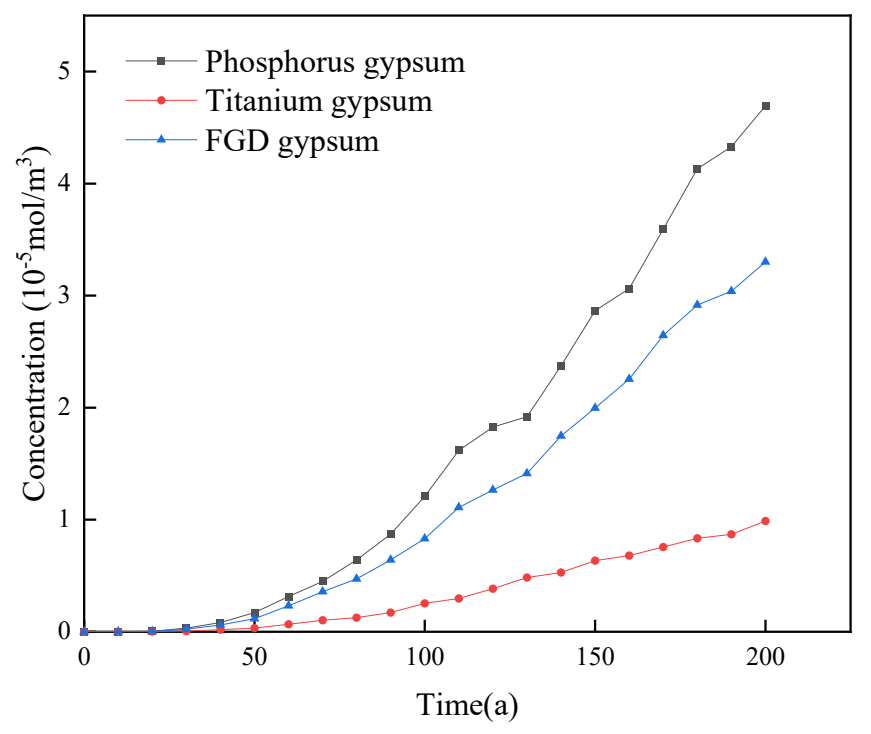

Fig.6 Concentration distribution curve of $\mathrm{Zn}$ at the observation point over time
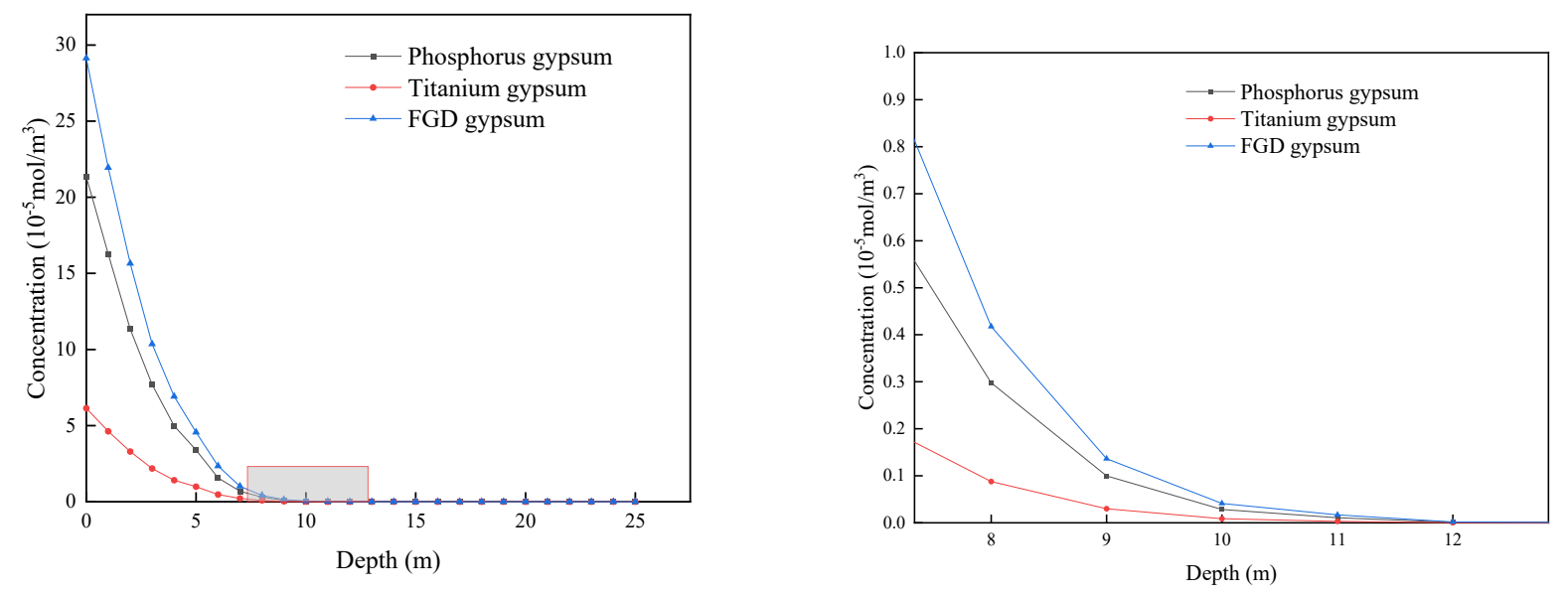

Fig.7 Concentration distribution of Zn at different depths

Figure 6 represents the concentration distribution curve of $\mathrm{Zn}$ at the observation point over time. During the filling process of three materials, the concentration of Zn gradually increased with time. When titanium gypsum is used as a filling material, the concentration of $\mathrm{Zn}$ element changes most gently, while when phosphorus gypsum and FGD gypsum are used as filling materials, the change of Zn element is relatively obvious. The order of concentration changes is phosphorus gypsum $>$ FGD gypsum $>$ titanium gypsum, and the concentrations of $\mathrm{Zn}$ in three materials at the end period of the simulation are $4.69 \times 10$ $5,3.30 \times 10-5$ and $9.89 \times 10-6 \mathrm{~mol} / \mathrm{m}^{3}$ respectively. This indicates that the diffusion rate and final concentration of metal elements are affected by the initial concentration during the migration process, and the concentration when element seepage reaches the bottom of the filling body is obviously lower than the initial concentration.

Figure 7 shows the concentration change curve of $\mathrm{Zn}$ as the migration depth increases at the end of this simulation, that is at 200a. during the process of gypsum filling, the concentration of metal elements all show a downward trend, especially in the case of phosphorus gypsum and FGD gypsum. In the initial 
stage of solute migration, due to the different initial concentrations, it can be clearly seen that the concentration distribution of $\mathrm{Zn}$ is different in different filling materials. The concentration of $\mathrm{Zn}$ in titanium gypsum has always been relatively smooth throughout the migration process. At a depth of about $10 \mathrm{~m}$, the concentration of $\mathrm{Zn}$ elements from titanium gypsum is close to 0 , and at the depth of $12 \mathrm{~m}$, the concentration of Zn elements from phosphorus gypsum and FGD gypsum is close to 0 . This indicates that the migration ability of $\mathrm{Zn}$ ions when titanium gypsum is used as filling material is weaker than when phosphorus gypsum and FGD gypsum are used.

\section{Conclusion}

During repeated contact with the leaching medium, the concentration of most of the metal elements released shows a downward trend, and the pH of most of most leachate is neutral or close to neutral. Alkaline conditions are not conducive to the leaching of harmful elements in phosphorus gypsum, titanium gypsum has a certain buffering effect on acid and FGD gypsum is more likely to release metal elements under low $\mathrm{pH}$. The concentration of metal elements in leachate of phosphorus gypsum, titanium gypsum and FGD gypsum is far lower than the identification standard for leaching toxicity of solid wastes, so none of the three have leaching toxicity characteristics and are not classified as hazardous wastes.

The simulation results of COMSOL show that for the abandoned coal mines studied in this study, during the 200-year period when the three gypsums were used as filling materials, the concentration of $\mathrm{Zn}$ measured at the observation point gradually increase with time; and as the depth increases, the migration ability of the elements gradually weakens, the concentration in titanium gypsum was close to 0 at a depth of $10 \mathrm{~m}$, and in phosphorus gypsum and desulfurized gypsum was close to 0 at a depth of $12 \mathrm{~m}$.

The results of leaching test and the numerical simulation indicate the three gypsums can be considered as filling material for abandoned mines, the diffusion rate, diffusion distance and final concentration of metal elements are affected by the initial concentration during the migration process.

\section{Acknowledgements}

The authors are grateful to the Xuzhou Key Social Research and Development Program (KC18134) for the financial support of this study

\section{Reference}

Bai H, Ma D, Chen Z (2013) Mechanical behavior of groundwater seepage in karst collapse pillars. Engineering Geology 164:101-106. https://doi.org/10.1016/j.enggeo.2013.07.003

Chindaprasirt P, Boonserm K, Chairuangsri T, Vichit-Vadakan W, Eaimsin T, Sato T, Pimraksa K (2011) Plaster materials from waste calcium sulfate containing chemicals, organic fibers and inorganic additives. Construction and Building Materials 25(8):3193-3203. https://doi.org/10.1016/j.conbuildmat.2011.03.004

Dutta B K, Khanra S, Mallick D (2009) Leaching of elements from coal fly ash: Assessment of its potential for use in filling abandoned coal mines. Fuel 88(7):1314-1323. https://doi.org/10.1016/j.fuel.2009.01.005

GB 5085.3-2007. Chinese National Standards. Identification standards for hazardous wastes-identification for extraction toxicity. China.

Hao Y, Li Q, Pan Y, Liu Z, Wu S, Xu Y, Qian G (2017) Heavy metals distribution characteristics of FGD gypsum samples from Shanxi province 12 coal-fired power plants and its potential environmental impacts. Fuel 209:238-245. https://doi.org/10.1016/j.fuel.2017.07.094

Hao Y, Wu S, Pan Y, Li Q, Zhou J, Xu Y, Qian G(2016) Characterization and leaching toxicities of mercury in flue gas desulfurization gypsum from coal-fired power plants in China. Fuel 177:157-163. https://doi.org/10.1016/j.fuel.2016.02.091 
Li L, Gao Q, Xiao B, Wen Z, Wu F (2020) Review and application prospevt of filling cementitious material developed by industrial solid waste. Mine R\&D 40(2):19-25

Ning X, Peng Y (2018) The study of polluted characterization on arsenic, lead and zinc in the vicinity of phosphogypsum deposition site. China Resources Comprehensive Utilization 36.10:29—34.

Song T, Huang Y, Zhang J, Li J (2018) Numerical simulation on migration effects of heavy metal elements in coal gangue backfilling body caused by the lithology of coal seam floor. Journal of China Coal Society 43(7):1983-1989

Sun J (2006) The performance of waste gypsum backfill material for pavement course and its safety assessment. Coal Ash China $1: 37-38$

Tayibi H, Choura, M., López, F. A., Alguacil, F. J., \& López-Delgado, A. (2009) Environmental impact and management of phosphogypsum. Journal of environmental management 90(8):2377-2386. https://doi.org/10.1016/j.jenvman.2009.03.007

Wei C, Sun Y, Gao X, Wang N (2015) Study on leaching characteristics of heavy metals in titanium gypsum. Environmental Engineering 5:131-135

Yang D (2018) Progress and prospect of resource utilization of phosphogypsum and titanium gypsum in China. Sulphuric Acid Ind 289:12-7

Zhang J, Liu F, Jiang J, Zhang B (2017) Experimental Study on the Mechanical Property of Composite Backfills with Phosphorus Gypsum. Metal Mine 1:47-50 


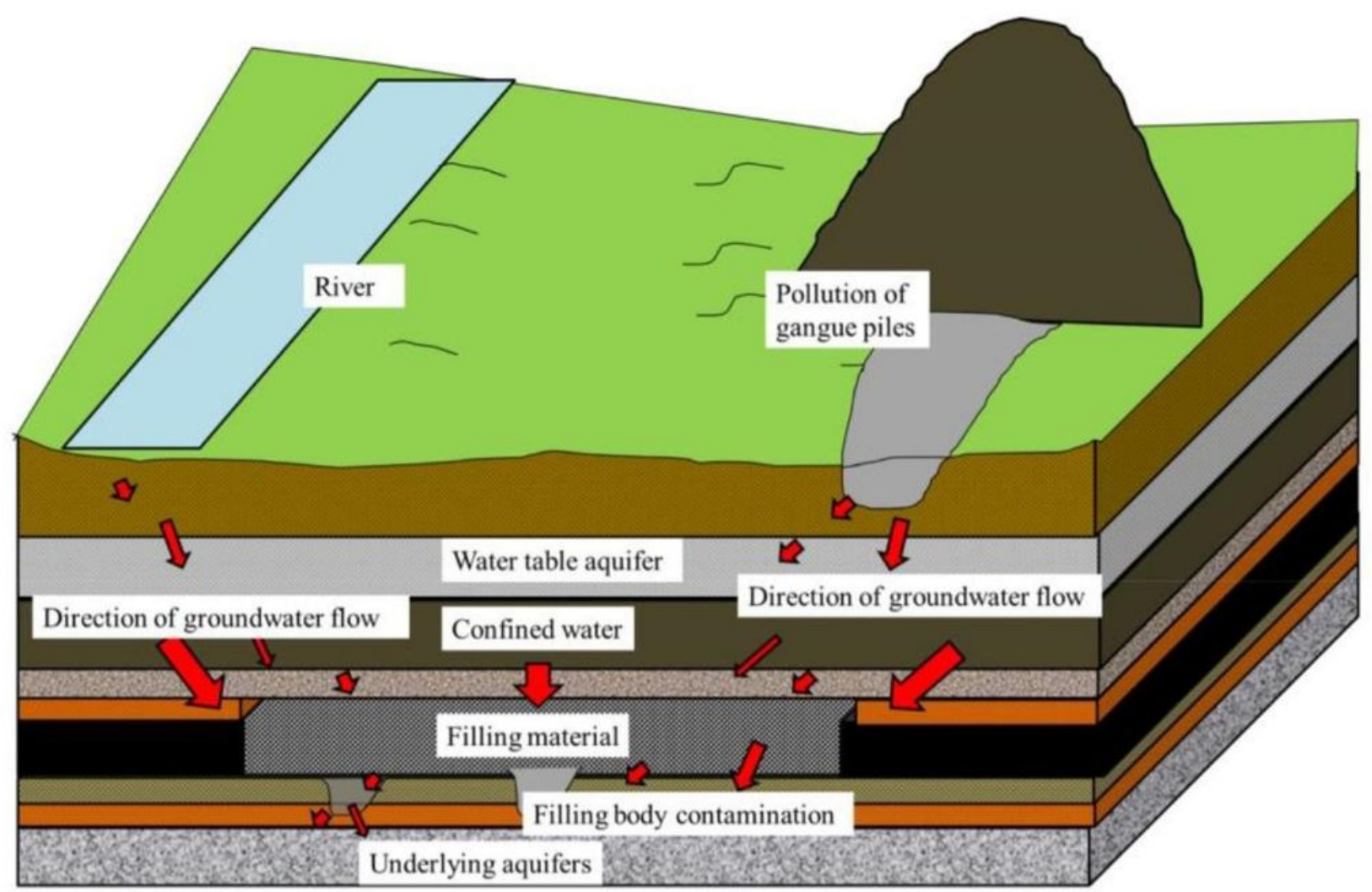

Figure 1

Potential effects of coal gangue in goaf on groundwater environmrnt

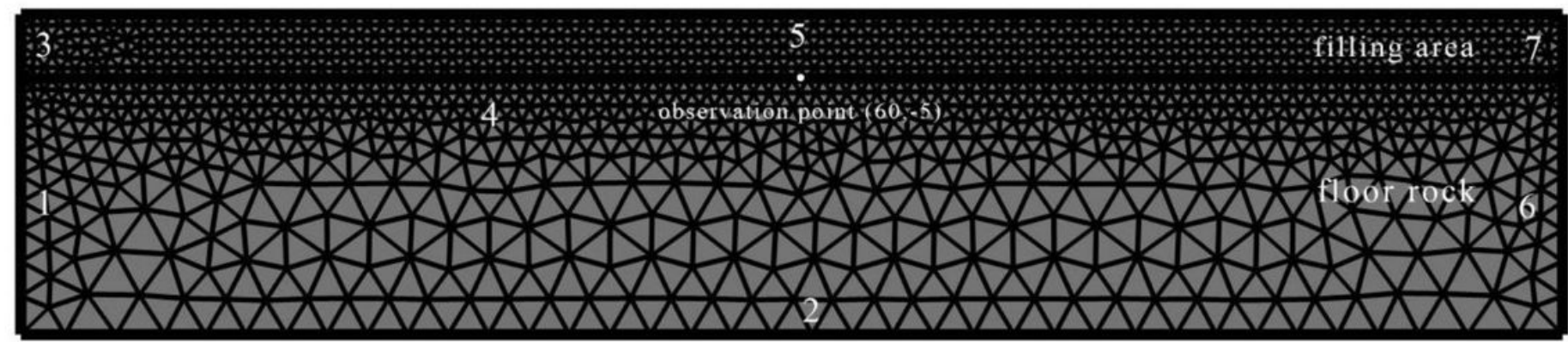

Figure 2

Filling mine numerical subdivision model 


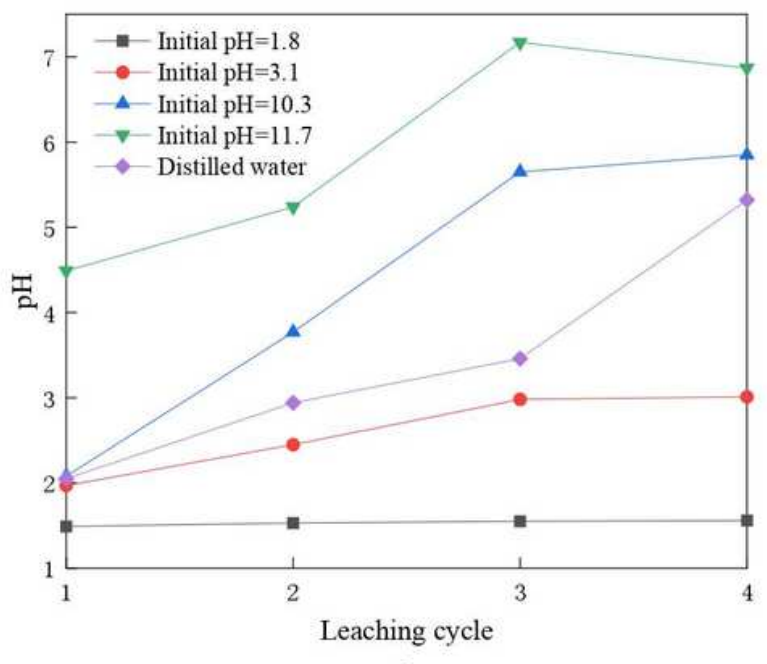

a

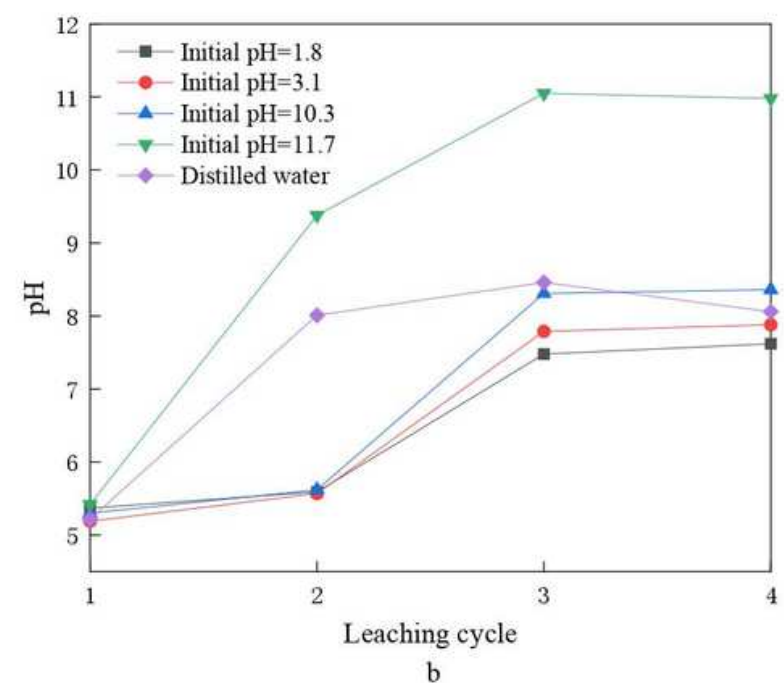

$\mathrm{b}$

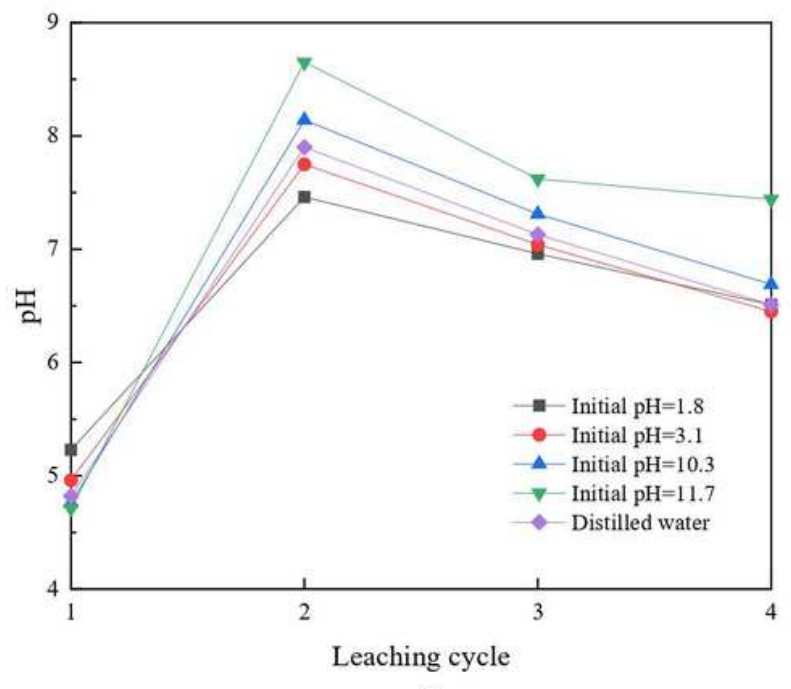

c

\section{Figure 3}

Change rule of $\mathrm{pH}$ of leachates (a: phosphorus gypsum 囚b:FGD gypsum c:titanium gypsum) 


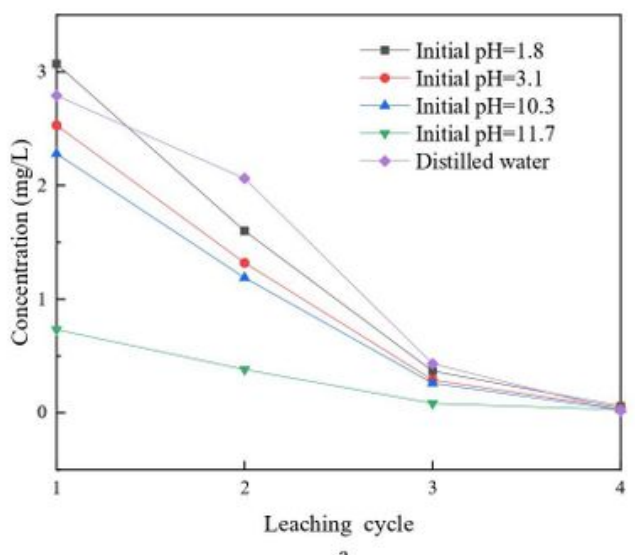

a

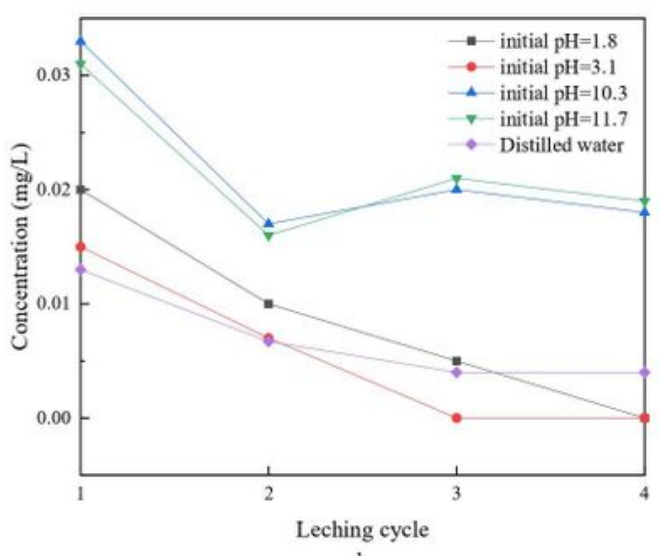

b

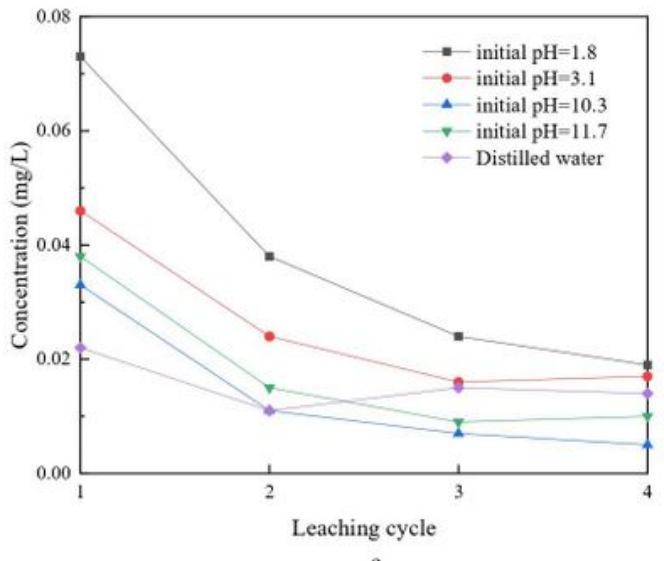

$\mathrm{c}$

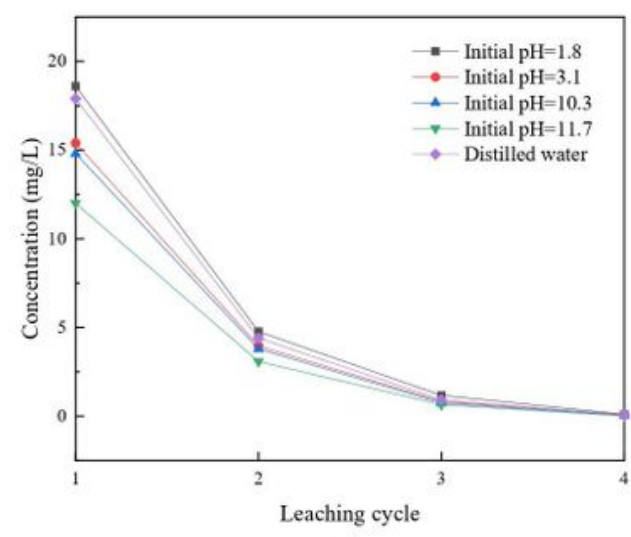

d

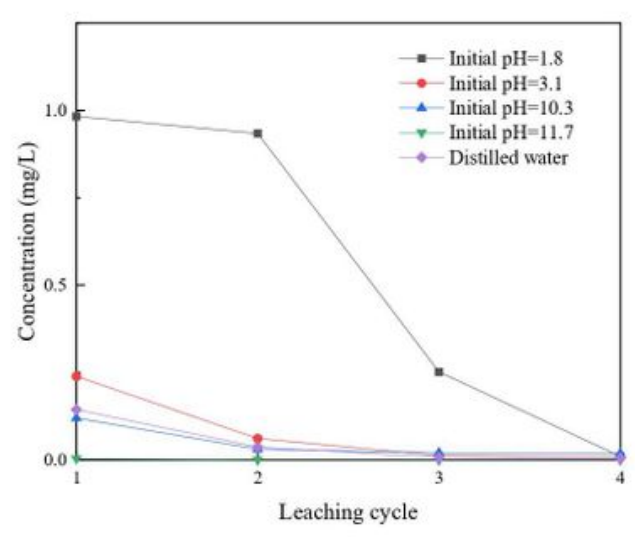

e

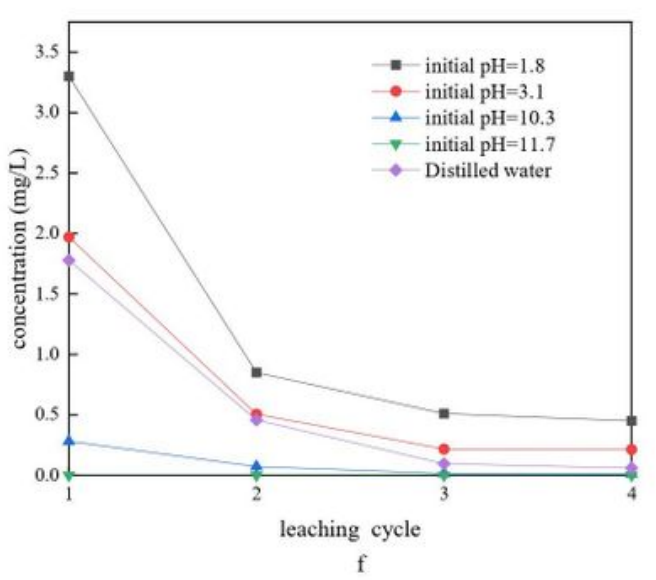

\section{Figure 4}

Leaching concentration of $\mathrm{Zn}$ in phosphorus gypsum(a), titanium gypsum(b) and FGD gypsum(c); leaching concentration of $\mathrm{Mn}$ in phosphorus gypsum(d), titanium gypsum(e) and FGD gypsum(f) 


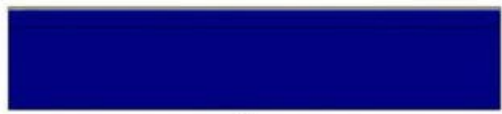

0a

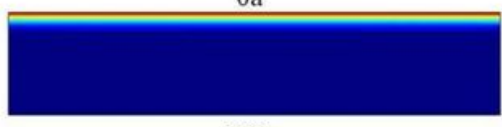

$100 \mathrm{a}$

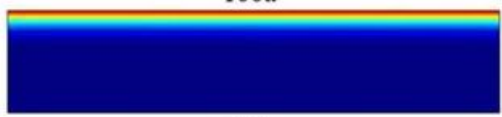

200a
FGD gypsum

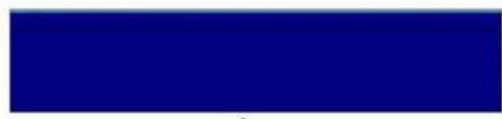

0a

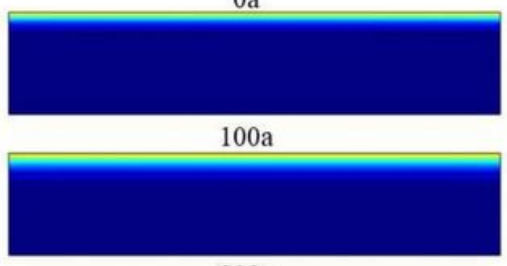

200a
Titanium gypsum

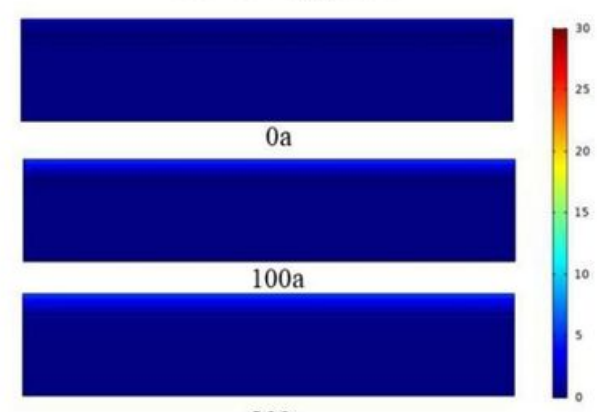

200a

Figure 5

Cloud map of Zn concentration distribution at $0 \mathrm{a}, 100 \mathrm{a}$ and $200 \mathrm{a}$. (10-5mol $\cdot \mathrm{m}-3)$

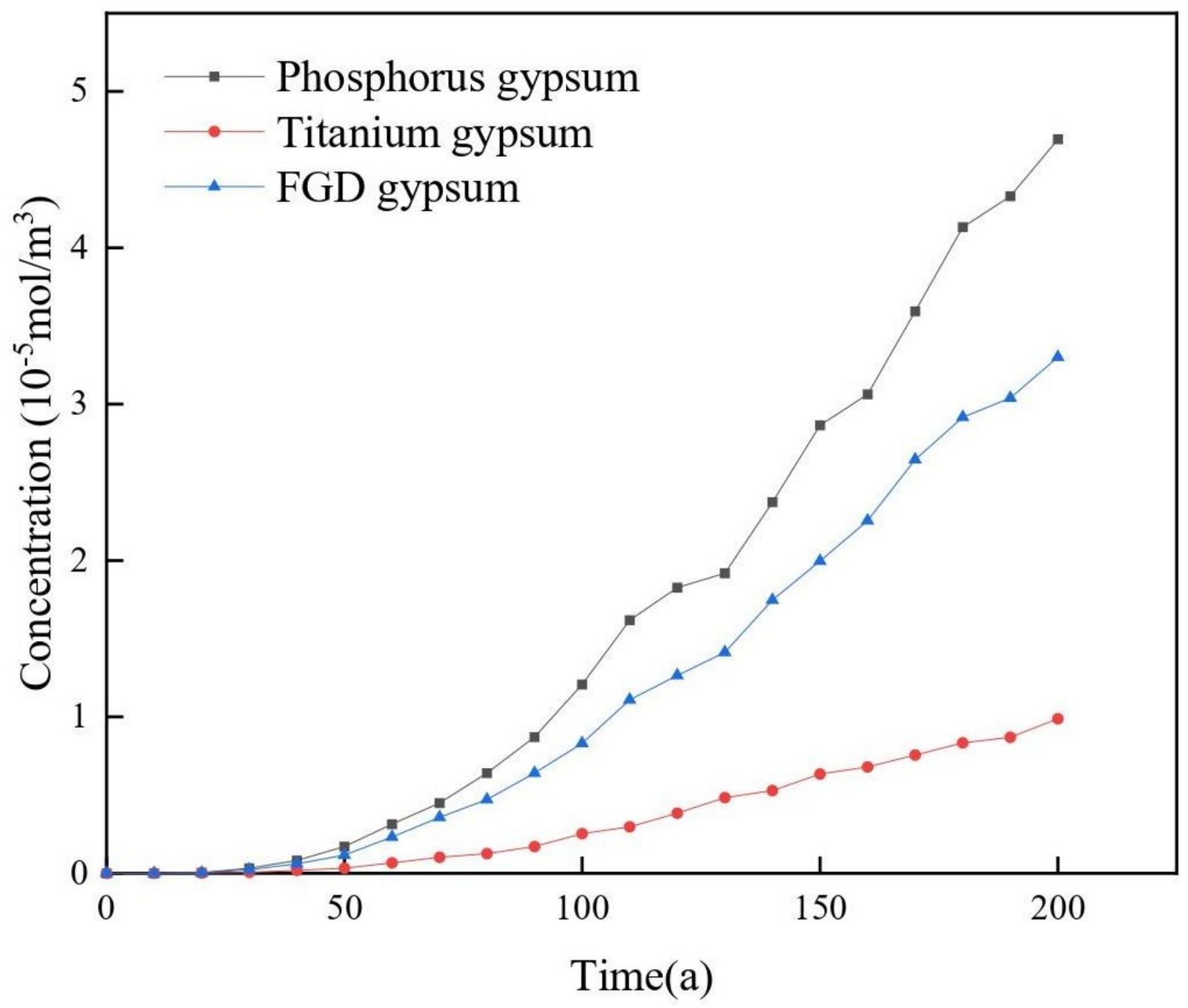


Figure 6

Concentration distribution curve of $\mathrm{Zn}$ at the observation point over time
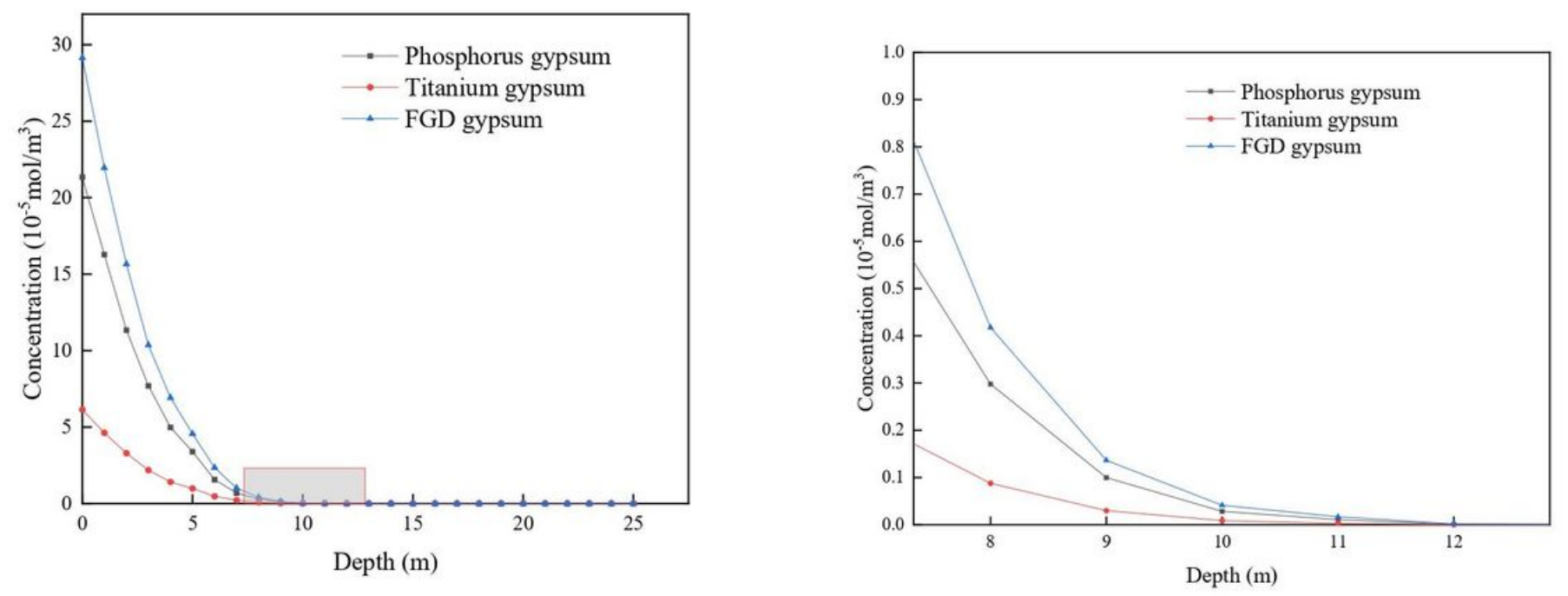

Figure 7

Concentration distribution of $\mathrm{Zn}$ at different depths 